Submission ID: 43872

\title{
Geologic-Geophysical Support of Drilling Horizontal Wells (LWD)
}

\section{S.V. Babenkov* (LUKOIL-Engineering Limited KogalymNIPIneft Branch in Tyumen)}

\section{SUMMARY}

There are many of factors, which should be taken in geophysical methods for study horizontal wells during drilling. They are bound with characteristic of using the software-hardware complex of GWS (geophysical well surveys), technology of works in the planning stages and carrying out of studies. Also factors are coupled with methodical dimensions of treatment and interpreting geological-geophysical information. Developing systems of fields with horizontal wells - is the most promising direction for involving the hard-torecover oil and gas reserves to the commercial production.

Geologic-geophysical support of drilling horizontal wells is managed round-the-clock for determining the optimal trajectory for the well's horizontal section to ensure greater productivity, as well as for effective realization of the objectives, which were planned. 
Геолого-геофизическое сопровождение скважин в процессе бурения горизонтальных стволов

С.В. Бабенков* (Филиал «ООО ЛУКОЙЛ-Инжиниринг» «КогалымНИПИнефть» в г. Тюмени)

\section{Введение}

Наиболее перспективным направлением по вовлечению в промышленную разработку трудноизвлекаемых запасов нефти является создание систем разработки нефтяных месторождений с использованием горизонтальных скважин (ГС).

С целью обеспечить оптимальную проводку горизонтального участка скважины в целевом интервале пласта и эффективную реализацию задач, поставленных при планировании скважины, бурение ГС и БСГО осуществляется с применением геолого-геофизического сопровождения бурения в круглосуточном режиме.

Для обеспечения непрерывного процесса сопровождения бурения в нашем Институте существует группа оперативного сопровождения бурения горизонтальных стволов скважин, которая включает в себя специалистов геологов и геофизиков. К настоящему времени пробурено более 1000 горизонтальных скважин по 30 месторождениям ООО «Лукойл Западная Сибирь». Бурение осуществляется в обширном интервале глубин и захватывает отложения от нижнего мела (группа пластов ВК) до доюрского комплекса (пласты группы ЮК0-ЮК11).

\section{Основа сопровождения}

Всю информацию, поступающую к специалистам, можно разделить на две группы: априорная - (предварительные данные по скважине) и информация, получаемая в процессе бурения скважины (в режиме псевдореального времени). Обе группы информации включают в себя 3 типа данных: геологический, геофизический, технологический. Без наличия этих данных процесс сопровождения бурения скважины невозможен.

Фундаментом сопровождения бурения той или иной скважины является подготовка априорной информации, в которой используется три блока данных:

- фонд скважин по окружению, который представлен полным комплексом ГИС, интерпретацией (разбивка на пропластки и выделение толщин пластов)

- трехмерная секторная геологическая модель (ГМ)

- пилотный ствол, отражающий актуальную, на момент бурения ГС, информацию о строении залежи.

Геолого-геофизические данные по скважинам окружения характеризуют начальные условия и отражают ситуацию верно только по литологии. Насыщение в таких скважинах не несет опорной информации. Это происходит из-за постепенного обводнения уже пробуренных скважин на месторождении.

Трехмерная секторная геологическая модель представляет собой актуализированный вариант локального участка модели, построенной в результате последней по времени оценки (переоценки) сырьевой базы месторождения (залежи) нефти. При обновлении модели учитывается вся новая информация по бурению, испытанию и исследованию скважин и вторых стволов, а также результаты других методов исследования недр, выполненных на участке планируемого бурения после актуализации модели.

Существует три фактора, влияющих на точность информации: наличие пилотного ствола, полнота комплекса кривых и положение ствола относительно траектории ГС. При ограниченном комплексе кривых (только ГК) пилот не выполняет свою функцию. Его положение считается оптимальным в случае бурения около точки входа в целевой пласт (Т1) (рис.1,2). Пилотный ствол, находящийся на расстоянии от планируемой ГС либо пробуренный на середине траектории, считается скважиной окружения. 


\section{EAGE}

EUROPEAN

ASSOCIATION OF

ENGINEERS

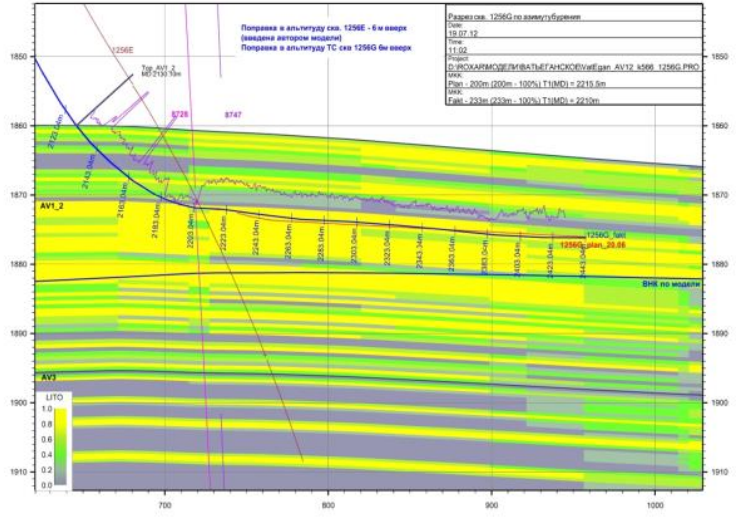

Рис.1. Разрез по азимуту бурения

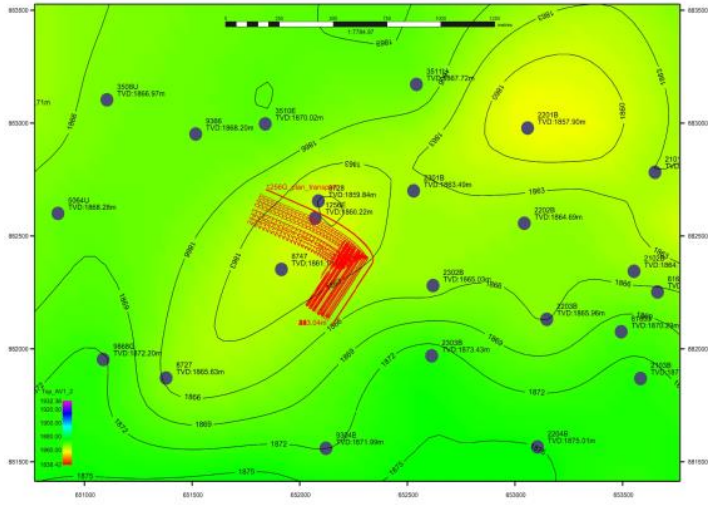

Рис.2. Структурная карта кровли пласта

На этапе актуализации исходной секторной геологической модели по результатам бурения пилотного ствола уточняется структурный план участка, положение газо-нефтяного и водо-нефтяного контактов залежи, кубы литологических и фильтрационно-емкостных свойств разреза, а также определяются литологические либо гипсометрические границы целевого интервала горизонтального участка скважины (БСГО) и координаты его ключевых точек Т1, $\mathrm{T} 2, \mathrm{~T} 3$. Уточненная секторная геологическая модель и рекомендации по границам целевого интервала и координатами ключевых точек передаются в НГДО.

На этапе бурения транспортного ствола скважины (ТC), после подготовки исходной информации для сопровождения, начинается этап корреляции и отбивки пластов-реперов (рис.3). Процесс бурения сопровождается регистрацией кривой ГК. По уровню глинизации увязка производится на явный, ярко выраженный репер, обеспечивающий определение текущего местоположения ГС, расстояния до цели и точки входа в целевой пласт.

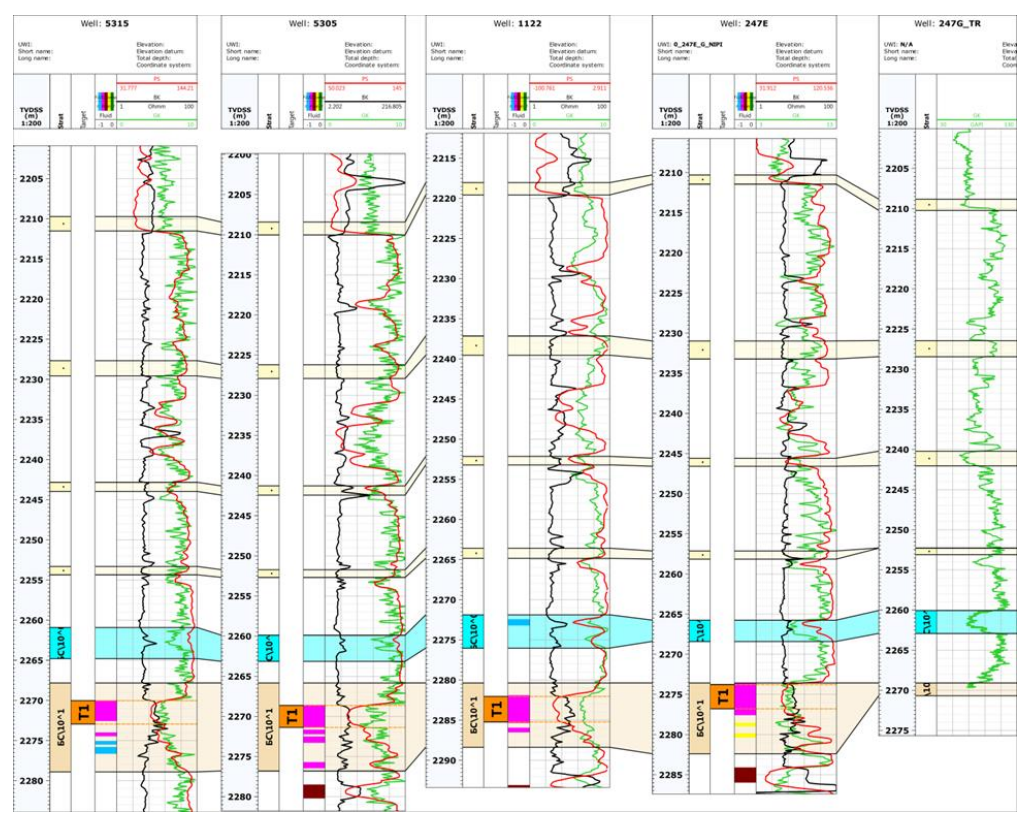

Рис.3. Схема корреляции, выделение опорных реперов.

С момента вскрытия целевого пласта начинается работа по подготовке скважины к проведению горизонтального участка. Проводка БСГО имеет существенное отличие от проводки ГС: БСГО бурится с ограниченным комплексом каротажа, а ГС с расширенным. Скважины с расширенным комплексом кривых не представляют трудности в определении ФЕС. Алгоритм для интерпретации ГС строится с использованием актуальных глав из отчетов по Подсчету Запасов (ПЗ). Отдельные разделы из глав содержат как современные данные, в которых проработаны все методики для определения ФЕС пласта, к которым вопросы не 
возникают, так и данные 90-х годов, в которых расчет ФЭС ведется только через метод ПС. Так же в $30 \%$ случаев отсутствует возможность определения какого либо из количественных параметров, расчет ведется по стандартным зависимостям, либо аналогам, которые влияют на достоверность полученных данных.

При сопровождении скважины с ограниченным комплексом (ГК, кривые сопротивления МВЭК - мультичастотный волновой электрический каротаж) отсутствует возможность построить определенный алгоритм. В связи с чем, для интерпретации БСГО существует своя система: данные с ПЗ объединяются с данными по окружению и актуализируются в процессе проводки скважины.

В случае отсутствия каких-либо данных происходят информационные потери, приводящие к риску неверной проводки бурящейся скважины. В процессе работы специалистами геофизиками отмечен ряд геолого-технологических проблем (ГТП). Проблемные ГС условно разделены на 3 группы и включают в себя скважины с ухудшенными геологическими, технологическими и геолого-технологическими условиями. Помимо этого на сопровождение ГС влияет ряд объективных и субъективных факторов.

Сложность при корреляции и отбивке пластов, связанная с геометрией пласта, относится к геологическим сложностям в процессе «привязки». Стоит отметить и тот факт, что при приближении к точке Т1 ГС меняет угол бурения, за счет этого меняется и поведение кривой ГК по отношению к вертикальным скважинам окружения. Использующиеся в процессе бурения ГУ данные ГТИ не всегда соответствуют показаниям каротажа.

Технологические проблемы включают в себя, в основном, качество априорной и предоставляемой информации. В некоторых случаях при проводке транспортного участка, а так же и при проводке ГУ, не соблюдается оптимальная скорость бурения, что приводит к искажению кривой. Так же к технологическим проблемам можно отнести разницу информации, поступающей в процессе бурения (по гидроканалу), и информации, извлекаемой из памяти прибора.

Основная проблема, возникающая при сопровождении бурения ГС у специалистов геологов - неподтверждение секторной геологической модели, обусловленное геологической неопределенностью.

Неподтверждение геологических моделей возникает в области:

- сейсмической основы в результате вскрытия скважинами продуктивного пласта на абсолютных отметках, отличающихся от прогнозных;

- площадей распространения нефтеносности залежи и нефтенасыщенных толщин, в связи с низкой песчанистостью или глинизацией пласта;

- ФЕС, что обусловлено ухудшением коллекторских свойств, а также обводнением в ходе разработки пласта.

При возникновении геологической неопределенности, проводится корректировка структурного каркаса, распределения литологии, положения ВНК на основе анализа вновь поступающей информации (рис.4). Дополнительным инструментом, при геологическом сопровождении бурения ГС является построение геонавигационной модели в режиме «псевдореального» времени.

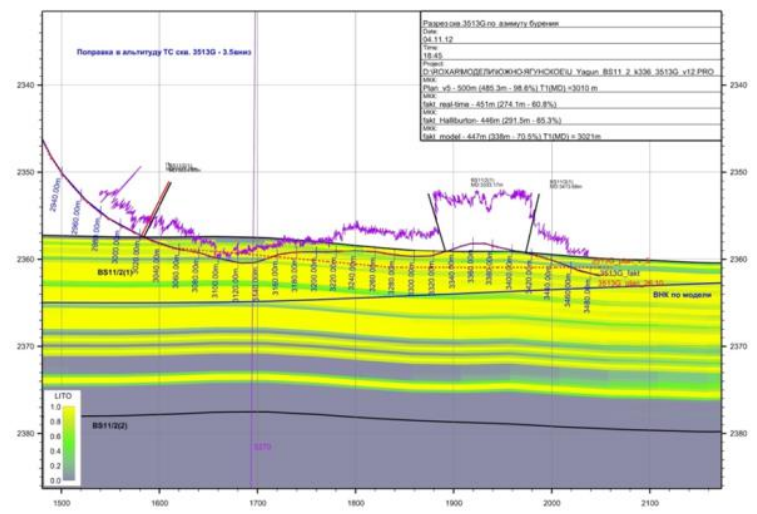

Рис.4. Корректировка структуры в процессе бурения 


\section{Выводы}

Одним из путей решения существующих проблем в проводке ТС и интерпретации является: проведение более широкого комплекса ГИС при неоднозначности разреза, при бурении транспортного ствола ГС на юрские продуктивные пласты, при проводке БСГО использование НКТ и зондов сопротивлений позволит оптимально вскрыть кровлю целевого объекта и корректно провести интерпретацию.

Бурение ГС сопровождается рядом проблем геологического и технологического характера. Поэтому снижение рисков, связанных с проводкой скважины может быть обеспечено при помощи:

- достаточного количества и качества априорной информации, что является определяющим фактором качества проводки ГС;

- проведения расширенного геофизического комплекса соответствующего сложности геологического разреза;

- использования современного программного и методического обеспечения.

\section{Литература}

1. Борисов Ю.П., Пилатовский В.П., Табаков В.П. Разработка нефтяных месторождений горизонтальными и многозабойными скважинами. - М.: Недра, 1964. - 154 с.

2. Алиев 3.С., Сомов Б.Е., Чекушин В.Ф. Обоснование конструкции горизонтальных и многоствольно-горизонтальных скважин для освоения нефтяных месторождений. - М.: Техника, 2001. - 192 с.

\section{References}

1. Borisov Y.P., Pylatovskiy V.P., Tabakov V.P. Development of oil deposits by horizontal and multilateral wells. - M.:Nedra, 1964. - 154 p.

2. Aliev Z.S., Somov B.E., Chekushin V. F. Justification of construction horizontal and multilateral wells for development oil deposits. - M.:Tehnika, 2001. - 192p. 